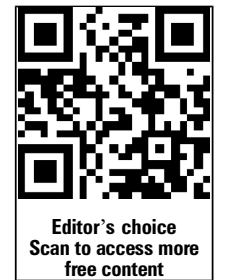

free content
- Additional material is published online only. To view please visit the journal online (http://dx.doi.org/10.1136/ injuryprev-2013-040823).

1 Injury Prevention Center of Greater Dallas, Dallas, Texas, USA

${ }^{2}$ Parkland Health and Hospital System, Dallas, Texas, USA ${ }^{3}$ Inspection and Life Safety Education Division, Dallas Fire Rescue Department, Dallas, Texas, USA

${ }^{4}$ The Southwestern Institute of Forensic Sciences, Office of the Medical Examiner, Dallas,

Texas, USA

${ }^{5}$ Vickery Meadow Youth Development Foundation, Dallas, Texas, USA

\section{Correspondence to}

Dr Gregory R Istre,

Injury Prevention Center of Greater Dallas, 6300 Harry Hines Blvd., Suite 240, Dallas, TX 75235, USA

greg.istre@phhs.org/gistre@ aol.com

Received 18 March 2013 Revised 13 June 2013 Accepted 14 June 2013 Published Online First 19 July 2013

\section{SLinked}

- http://dx.doi.org/10.1136/ injuryprev-2013-040824

To cite: Istre GR, McCoy MA, Moore BJ, et al. Inj Prev 2014;20:97-102.

\title{
Preventing deaths and injuries from house fires: an outcome evaluation of a community-based smoke alarm installation programme
}

\author{
Gregory R Istre, ${ }^{1}$ Mary A McCoy, ${ }^{1}$ Billy J Moore, ${ }^{2}$ Carey Roper, ${ }^{3}$ \\ Shelli Stephens-Stidham, ${ }^{1}$ Jeffrey J Barnard, ${ }^{4}$ Debra K Carlin, ${ }^{3}$ Martha Stowe, ${ }^{1,5}$ \\ Ron J Anderson ${ }^{2}$
}

\section{ABSTRACT \\ Background Few studies have examined the impact of community-based smoke alarm (SA) distribution programmes on the occurrence of house fire-related deaths and injuries (HF-D/I).}

Objective To determine whether the rate of HF-D/l differed for programme houses that had a SA installed through a community-based programme called Operation Installation, versus non-programme houses in the same census tracts that had not received such a SA.

Methods Teams of volunteers and firefighters canvassed houses in 36 high-risk target census tracts in Dallas, TX, between April 2001 and April 2011, and installed lithium-powered SAs in houses where residents were present and gave permission. We then followed incidence of HF-D/l among residents of the 8134 programme houses versus the 24346 non-programme houses.

Results After a mean of 5.2 years of follow-up, the unadjusted HF-D/I rate was $68 \%$ lower among residents of programme houses versus non-programme houses (3.1 vs 9.6 per 100000 population, respectively; rate ratio, $0.32 ; 95 \% \mathrm{Cl} 0.10$ to 0.84 ). Multivariate analysis including several demographic variables showed that the adjusted HF-D/l rate in programme houses was $63 \%$ lower than non-programme houses. The programme was most effective in the first 5 years after SA installation, with declining difference in rates after the 6th year, probably due to SAs becoming non-functional during that time.

Conclusions This collaborative, community-based SA installation programme was effective at preventing deaths and injuries from house fires, but the duration of effectiveness was less than 10 years.

\section{INTRODUCTION}

House fires continue to be a major cause of deaths and injuries in the USA, accounting for more than 2600 deaths and 13000 injuries in 2010. ${ }^{1}$ Smoke alarms are one of the mainstays of prevention of these deaths, but many houses still do not have functional smoke alarms, especially those at highest risk. ${ }^{2-4}$ One approach to increasing the prevalence of smoke alarms in high-risk houses, is through community-based smoke alarm installation programmes ${ }^{5-8}$ but there are few studies that have evaluated the impact of such programmes on the rate of fire deaths and injuries. ${ }^{79} 10$ One study in the USA showed a significant decrease in injury rates after the programme ${ }^{8}$; however, a critique of the study raised the issue of possible biases, including regression to the mean, in that before/after evaluation. ${ }^{11}$

Based on an initial epidemiologic study of house fire-related deaths and injuries in $1990 \mathrm{~s},{ }^{12}$ we designed a targeted, community-based intervention called Operation Installation (OI) to install smoke alarms in high-risk census tracts in Dallas, TX high-risk tracts included those tracts that had been previously identified as having high rates of house fire-related deaths and injuries, and that had lowest median income. We evaluated the impact of this programme on house fire-related deaths and injuries using a cohort approach which, to our knowledge, has not been done previously, to evaluate a smoke alarm installation programme.

\section{METHODS}

\section{Intervention: operation installation}

OI has been a joint project of the Injury Prevention Center of Greater Dallas (IPC), the Dallas Fire Rescue Department (DFRD), and the Dallas chapter of the American Red Cross (ARC). With each OI, volunteers assist DFRD firefighters and prevention staff as they go into homes to install smoke alarms and collect information about each home. OI was patterned after the Oklahoma City programme that was begun in $1990,{ }^{8}$ the main difference being that in OI, all smoke alarms have been installed by OI personnel, and used only lithium-powered ionisation-type smoke alarms (see online supplementary appendix 1 for more details). Target census tracts were chosen because they were high-risk tracts, which included those with rates in the upper quartile during the 1991-1997 study, and those with income in the lowest quartile. ${ }^{12}$

Setting and participants: definitions of programme population, non-programme population and cohort denominators

For purposes of this study, a house was defined as a single-family or two-family dwelling (eg, a house or a duplex). A programme house was defined as one that received at least one smoke alarm through OI; a non-programme house was any other house in the same census tract that did not receive a smoke alarm through OI. Information about programme households (programme population cohort) was measured directly by surveys that were completed by volunteers with OI, at the time of installation of the smoke alarm. Information collected on the 
survey form for each programme house included address, type of residence (house, duplex), whether the residence was rented versus owned, number of residents who lived in house, number of residents who were $>64$ years old and the number $<5$ years old, and the race/ethnicity of the head of the household, among other variables. Missing data for the number of persons residing in the house were managed with a multiple imputation technique. For non-programme population cohort, aggregated survey results for programme houses were subtracted from the aggregated totals for that census tract estimate for the house/ duplex population for the year that OI was carried out in the tract. See supplementary appendix 2 for more details.

\section{Case definition/outcome measures}

For the outcome measure for this study, we defined a 'case 'as a house fire-related death or injury (HF-D/I) in one of the 36 target census tracts. A death was defined as a person who the Dallas County Medical Examiner determined to have died from a house fire that occurred in a target census tract, and a nonfatal injury was defined as a person who was injured but did not die from a house fire that occurred in a target census tract, and who was identified through the Emergency Medical Services database as having been transported by ambulance to a hospital (see online supplementary appendix 3 for more details).

\section{Study period}

OI first took place in October of 1999, but we did not begin systematically collecting data with a standardised survey form until 28 April 2001, which is the date we used as the beginning of this study. For each census tract, the study period began on the date of OI in the census tract, and ended on 4/27/2011 (10 years after the first OI of this study) or when a 2 nd OI was done (which occurred in three census tracts), whichever was first. The follow-up period varied for each tract depending on the date of OI. Follow-up duration ranged from 10 years in the earliest tract, to 2.5 months in the latest OI tract.

\section{Smoke alarm follow-up surveys}

Eight hundred randomly sampled houses that had received smoke alarms through OI approximately 2, 4, 6, 8 and 10 years previously, were revisited by DFRD personnel to assess presence and functioning of the OI smoke alarms that had previously been installed. These methods are detailed in a companion paper. $^{13}$

\section{Statistical analysis}

Rates were calculated as cases per 100000 person-years of follow-up. Comparisons of unadjusted rates were done as rate ratios (RRs), with a conditional maximum likelihood estimate of the RR with exact confidence limits. ${ }^{14}$ The preventive fraction in the exposed population (the programme population), which is a measure of the efficacy of the intervention, was calculated as 1 minus the rate ratio.

To calculate adjusted rates for comparison of programme and non-programme house population, we performed a multivariate analysis that treated the programme and non-programme population rates as collected from two independent samples. Each rate was weighted for the size of the denominator (ie, the number of person-years for programme and non-programme populations in the tract). The analysis fit a multiple regression model, with programme and non-programme case rates for each census tract as the dependent variable, an indicator variable for programme and non-programme populations, and the demographic variables listed in table 1 for the programme and the
Table 1 Baseline characteristics for programme and non-programme populations*

\begin{tabular}{|c|c|c|c|}
\hline & $\begin{array}{l}\text { Programme } \\
\text { houses }\end{array}$ & $\begin{array}{l}\text { Non-programme } \\
\text { housest }\end{array}$ & Total \\
\hline Number of homes & 8134 & 24346 & 32480 \\
\hline Population & 28570 & 79135 & 107705 \\
\hline $\begin{array}{l}\text { Mean (number of persons/ } \\
\text { house) }\end{array}$ & 3.5 & 3.3 & 3.3 \\
\hline $\begin{array}{l}\text { Number of smoke alarms } \\
\text { installed }\end{array}$ & 20127 & - & \\
\hline Mean (\#SD/house) & 2.5 & - & \\
\hline \multicolumn{4}{|c|}{ Households (\% with characteristic) } \\
\hline Owned residence & 71.1 & 63.7 & 65.6 \\
\hline Black HH & 47.6 & 52.7 & 51.4 \\
\hline Hispanic HH & 43.5 & 35.5 & 37.5 \\
\hline $\mathrm{HH}>64$ years & 31.3 & 21.0 & 23.6 \\
\hline Owned and $\mathrm{HH}>64$ years & 26.8 & 16.9 & 19.4 \\
\hline Rented and $\mathrm{HH}>64$ years & 4.5 & 4.1 & 4.2 \\
\hline \multicolumn{4}{|c|}{$\begin{array}{l}\mathrm{p}<0.05 \text { for all comparisons of household characteristics between programme and } \\
\text { non-programme house populations, except rented and } \mathrm{HH}>64 \text { years, which was } \\
\text { non-significant. } \\
{ }^{*} 36 \text { Target census tracts. } \\
\text { †See text for methods of calculating non-programme population. } \\
\text { HH, Head of household. }\end{array}$} \\
\hline
\end{tabular}

non-programme populations as covariates. Thus, case rates for programme and non-programme populations were adjusted for the size of the populations and the follow-up duration and the percentages of rental versus owned houses, head of household being African-American or Hispanic, or being elderly (>64 years), as well as elderly and rented or elderly and owned houses.

A secondary analysis used the difference between case rates for programme versus non-programme populations in a paired comparisons methodology to assess case rate difference for each of the 36 census tracts. Online supplementary appendix 4 contains more details of the analyses.

Data were analysed with Epi Info (TM) 3.5.3 (CDC, Atlanta, Georgia, USA) and STATA V.11.2 (STATA, College Station, Texas, USA). For the cumulative case rate graph, rates over time for the programme and non-programme populations were compared by the Kolmogorov-Smirnov equality of distributions test. ${ }^{15}$

\section{RESULTS}

\section{Programme and non-programme populations}

During the study period, OI was performed in 36 census tracts, containing 32480 houses with a population of 107705 persons. A total of 20127 smoke alarms were installed in 8134 houses (mean, 2.5), occupied by a population of 28570 ; these comprised the programme population. The non-programme population consisted of 24346 houses, with a population of 79135 (table 1).

\section{Study period case rates}

For the study period in the 36 target census tracts, there were 42 cases (26 deaths/16 injuries). Mean age was 48.6 years (range, 0-90 years, with age unknown for one case) and was similar for deaths and injuries. Twenty-three cases (54.8\%) were female. African-Americans accounted for 26 (61.9\%) cases, $9(21.4 \%)$ were white, 4 (9.5\%) Hispanic, and 3 cases (7.1\%) were of unknown race/ethnicity. Of the 26 deaths, 17 died at the scene of the house fire, and 9 died after transport to a 
hospital. Of the 16 non-fatal injuries, 8 were admitted to a hospital, and 8 were seen in an emergency department (ED) and not admitted to a hospital.

Target tracts were followed for a mean of 5.2 years (range, 0.2 to 10 years) after OI, and resulted in 523305 person-years of follow-up, for a crude rate of 8.0 cases per 100000 person-years. Four cases (two deaths and two injuries) occurred in the programme population for a crude rate of 3.1 cases per 100000 person-years, and 38 cases ( 24 deaths and 14 injuries) occurred in the non-programme population, for a crude rate of 9.6 cases per 100000 person-years (RR, $0.32,95 \% \mathrm{CI}, 0.10$ to 0.84 ). The rate difference was 6.5 per 100000 population $(95 \% \mathrm{CI}, 2.1$ to $10.8)$, with an attributable preventive fraction of $67.6 \%(95 \%$ CI, $9.2 \%$ to $88.4 \%$ ) for the programme population (table 2). For fatal cases, the preventive fraction in the programme population was $74.3 \%$ (rate: 1.6 vs 6.1 per 100000 population, respectively; RR, 0.26 , 95\% CI 0.04 to 0.93 ). For non-fatal cases the preventive fraction was $56 \%$ (rate: 1.6 vs 3.5 per 100000 population, respectively; RR, 0.44 , 95\% CI 0.07 to 1.7 ).

For the first 5 years of follow-up, the case rate in the programme population was significantly lower than in the nonprogramme population (1.0 vs 9.8 per 100000 population, respectively; $\mathrm{RR}=0.1,95 \% \mathrm{CI} 0.01$ to 0.74 ; attributable preventive fraction $=90 \%$ ), but it was not for the second 5 years of follow-up (11.1 vs 9.0 per 100000 population, respectively; $\mathrm{RR}=1.2,95 \%$ CI 0.3 to 4.4 ).

Of the four cases that occurred in programme houses, one occurred during the first 5 years after OI, and the smoke alarm functioned. Three cases occurred during the second 5 years, and none of the smoke alarms functioned (in two, the smoke alarm was present but not working, and in one, the alarm was not present). Each of the latter three cases had received only one smoke alarm thru OI.

\section{Cumulative incidence}

The cumulative incidence for the programme and nonprogramme populations (figure 1) showed a significant difference between the two groups $(p<0.02$, by KolmogorovSmirnoff equality of distributions test). Additionally, the graph

Table 2 Incidence rates of cases, for programme and non-programme populations

\begin{tabular}{|c|c|c|c|}
\hline & $\begin{array}{l}\text { Programme } \\
\text { houses }\end{array}$ & $\begin{array}{l}\text { Non-programme } \\
\text { houses* }\end{array}$ & Total \\
\hline Number of homes & 8134 & 24346 & 32480 \\
\hline Population & 28570 & 79135 & 107705 \\
\hline Mean (\#persons/house) & 3.5 & 3.3 & 3.3 \\
\hline $\begin{array}{l}\text { Number of smoke alarms } \\
\text { installed }\end{array}$ & 20127 & - & \\
\hline Mean (\#SD/house) & 2.5 & - & \\
\hline Person-years of follow-up & 128333 & 394972 & 523305 \\
\hline \multicolumn{4}{|l|}{ Cases } \\
\hline Number of deaths & 2 & 24 & 26 \\
\hline Number of injuries & 2 & 14 & 16 \\
\hline Total & 4 & 38 & 42 \\
\hline Ratet $(95 \% \mathrm{Cl})$ & $\begin{array}{l}3.1(0.8 \text { to } \\
8.0)\end{array}$ & 9.6 (6.8 to 13.3$)$ & $\begin{array}{l}8.0(5.8 \text { to } \\
10.9)\end{array}$ \\
\hline
\end{tabular}

Includes 36 Target census tracts.

* See text for methods of calculating non-programme population.

tPer 100000 person-years. For comparison of programme versus non-programme

houses: Rate ratio $=0.32(95 \% \mathrm{Cl} 0.10$ to 0.84$)$; Preventive fraction in programme

population: $68 \%$ (95\% Cl 9.2 to $88.4 \%)$. appears to have a changing slope of incidence for the programme population in the later years of the study, with a declining difference between the two groups starting at about the seventh year of the study.

\section{Multivariate analysis}

From the multivariate analysis, the adjusted case rate in the programme population was lower than the non-programme population (3.5 vs 9.5 , respectively, rate difference $6.0 ; 95 \%$ CI 0.8 to 11.1; $\mathrm{RR}=0.37,95 \% \mathrm{CI} 0.00$ to 0.86 ), as listed in table 3 . The rates for programme versus non-programme populations were significantly different for the first 5 years of follow-up $(\mathrm{p}<0.01)$, but not for the second 5 years.

Results of the paired comparisons analyses for the full 10-year period (adjusted rate difference 5.1, 95\% CI 2.7 to 7.5 ) were similar to results of the overall adjusted analysis, although somewhat more pronounced and with wider CIs, and also was significant for the first 5 years $(p<0.001)$ but not for the second 5 years.

\section{Smoke alarm prevalence}

Among the 800 houses that were revisited in the random sample, the proportion of houses that had at least one working OI smoke alarm was substantially lower in years 6,8 and 10 than in the 2-year and 4-year strata (figure 2).

\section{DISCUSSION}

To our knowledge, this is the first study to look at the impact of a smoke alarm installation programme using population-based rates of house fire-related deaths and injuries in houses that received a smoke alarm (programme houses) versus houses in the same neighbourhoods that did not receive one (nonprogramme houses). The unadjusted case rate in programme homes was $68 \%$ lower than non-programme homes, and the multivariate-adjusted rates showed a similarly lower rate in programme homes, translating to a programme efficacy of $>60 \%$. We found significantly lower case rates in programme homes in all four analyses that were done.

One previous randomised study in the UK showed no difference in injuries or deaths for neighbourhoods that had a smoke alarm distribution programme. ${ }^{16}$ However, that study did not install the alarms, and few of the alarms handed out were ever installed, which probably accounted for the lack of effect of the programme. Our study documented the presence of a high proportion of functioning alarms in a sample survey 2 years after the programme.

The efficacy found in our study was comparable with that found by Mallonee et al, in a smoke alarm giveaway programme in Oklahoma City in $1990 .^{8}$ That study has been criticised because its design could not exclude regression to the mean as an explanation for the drop in death and injury rates. ${ }^{11}$ Our design sought to eliminate the issue of regression to the mean, by following two cohorts (programme and non-programme homes) through the same time periods. Even so, we found no evidence of regression to the mean for the case rates for study census tracts, between the 1990s and the 2000s.

The Oklahoma City programme followed homes for about 4 years, used alkaline battery-powered smoke alarms, and documented the presence of functioning alarms in a majority of programme houses after the distribution effort. ${ }^{8}$ That study found a $77 \%$ lower rate in the target zip codes 4 years after the programme. We found a similar lower rate in programme homes for the first 5 years of the study (9.8 vs 1.0 , an $89 \%$ lower rate in programme homes).

We were hopeful that by using lithium-powered smoke alarms, our programme would sustain its efficacy longer. 
Figure 1 Cumulative incidence rate of house fire-related cases, According to study group, for houses in target census tracts. Cases were defined as a death or non-fatal injury related to a house fire. Programme houses had received a smoke alarm through Operation Installation, between 2001 and 2011. Non-programme houses were all other houses in the same census tracts, that did not receive a smoke alarm through Operation Installation.

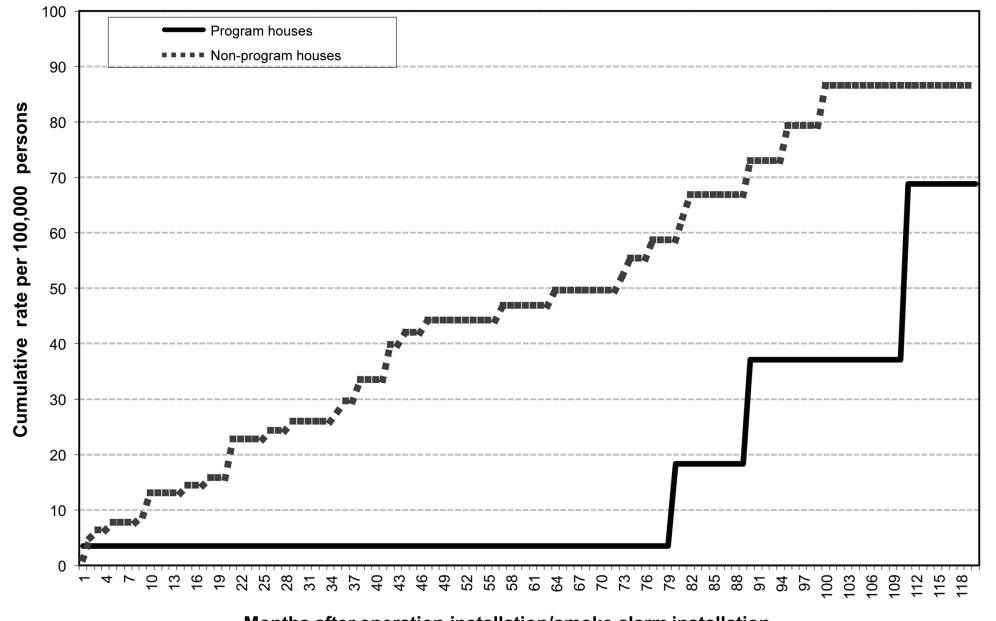

Months after operation installation/smoke alarm installation

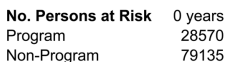
0 years
28570
79135
4 years
14757
45322
However, the efficacy of OI seems to have dropped during the second 5 years of follow-up. There was a marked difference in incidence case rates between the first 5 years and the second 5 years in the programme population, with an apparent change in the cumulative incidence curve at about 6-7 years. This may have been due to non-functioning of smoke alarms over the years. Although lithium-powered alarms are supposed to function for 10 years, it was apparent from our follow-up testing that they do not. Although $>90 \%$ of the programme houses had at least one working smoke alarm at the 2-year follow-up sample, that proportion was down to $20 \%$ for the 10 -year sample. ${ }^{13}$ This is similar to the findings of Jackson et al, ${ }^{17}$ that only about one-third of lithium-powered smoke alarms were still functioning after 10 years.

In our study, there were four 'failures' with deaths or injuries in programme houses; three occurred late, in years 7-10 of the study; for all three, the original OI smoke alarm was nonfunctional (two cases) or had been removed (one case), and there was no other functional smoke alarm in the residence at the time. Each had received only one smoke alarm through OI. Installing more than one alarm likely would have increased the odds that at least one alarm would be working after several years. The results support the recommendation for regular monitoring of smoke alarms to assure that they are functioning, ${ }^{3}$ even when lithium powered. This also has important implications for planning of repeat smoke alarm installation programmes in communities that implement such programmes.

There are several limitations of our study. The study was not randomised, and although programme and non-programme houses were on same blocks and in the same census tracts, they may have differed in important ways that we did not measure, such as the prevalence of smoking, poverty, or pre-existing smoke alarms. It is possible that persons in programme houses were inherently at lower risk of fire-related death or injury, and selfselected into the programme. However, the multivariate analyses, which attempted to control for factors such as race, ownership status, elderly household member and so on, confirmed the significance of the finding from the crude rate analysis, implying that the programme and non-programme populations were not dissimilar despite not being randomised. Additionally, the case rate in the programme population for the second 5 years of follow-up was as high as the non-programme population, coinciding with a time when many of the smoke alarms had ceased to function. Another potential limitation is that the population of non-programme homes was calculated using census data, rather than by direct measurement. Inaccuracies in the census data could have overestimated or underestimated the population, leading to errors in calculations of rates for this comparison group. We attempted to minimise the differences in census counts by making interpolated estimates of the population for the year of OI. The number of residents per home was similar for the programme and nonprogramme populations, and case rate for the non-programme population (9.6 per 100000 population) was similar to the prestudy case rate $(9.3$ per 100000$)$, prior to the intervention. Additionally, it is possible that our surveillance may have missed some cases of non-fatal injury, thus underestimating case rates; however, this would likely have been similar for the programme or non-programme populations, and when we analysed only fatal cases, the effectiveness remained significant. And finally, it is possible that some of the impact of the intervention resulted from the brief on-site education that was done at the time of smoke alarm installation. We could not separate the impact of the educational component of the programme and the resulting awareness, from the actual installation of the smoke alarms.

Table 3 Comparison of case rates for programme and non-programme populations, including unadjusted and adjusted rates, rate differences and rate ratios

\begin{tabular}{llllll}
\hline & Rate* in programme houses & Rate* in non-programme houses & Rate difference & Rate ratio & Preventive fraction \\
\hline Unadjusted $(95 \% \mathrm{Cl})$ & $3.1(0.8$ to 8.0$)$ & $9.6(6.8$ to 13.3$)$ & $6.5(2.2$ to 10.8$)$ & $0.32(0.10$ to 0.84$)$ & $68 \%(9.2$ to $88.4 \%)$ \\
Adjustedt $(95 \% \mathrm{Cl})$ & $3.5(0$ to 8.2$)$ & $9.5(7.3$ to 11.7$)$ & $6.0(0.8$ to 11.1$)$ & $0.37(0.00$ to 0.86$)$ & $63 \%(16$ to $100 \%)$ \\
\hline
\end{tabular}

*Per 100000 person-years.

†Multivariate regression analysis using independent samples approach, controlling for size of the populations and the follow-up duration and the percentages of rental versus owned

houses, head of household ( $\mathrm{HH}$ ) being African-American or Hispanic, $\mathrm{HH}$ being elderly (>64 years), as well as elderly $\mathrm{HH}$ and rented or elderly $\mathrm{HH}$ and owned houses (see text). 
Figure 2 Proportion of houses that still had at least one working smoke alarm, by years, since installation, for programme houses that received at least one smoke alarm through Operation Installation, Dallas, TX, $\mathrm{n}=800$. Adapted from McCoy et $\mathrm{I}^{13}$; companion paper.

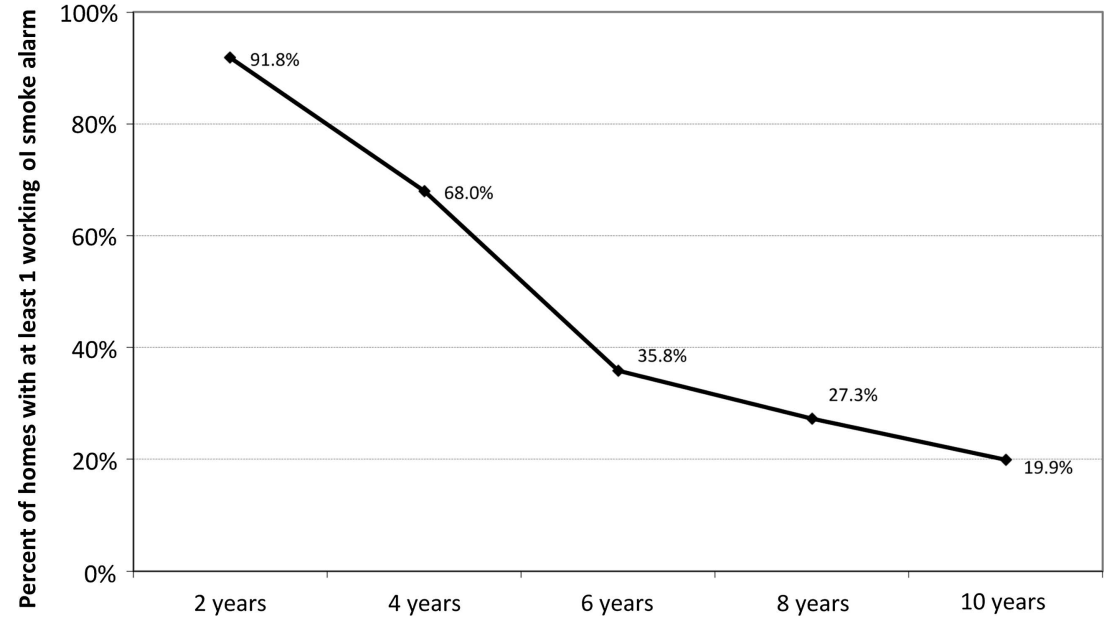

Years since installation
These results were the culmination of a typical public health approach to prevention: identifying a problem and the populations at risk, designing and implementing an intervention, and then monitoring outcomes to evaluate its impact. Even so, it required more than 10 years of implementation and follow-up to document its efficacy, a difficulty that is inherent in using relatively rare events such as house fire deaths and injuries as outcome measures. Nevertheless, the results reinforce the value of a community-based smoke alarm installation programme to decrease deaths and injuries from house fires, and point out the importance of long-term support for their implementation. 7 18

\section{What is already known on the subject}

- Smoke alarms are well documented to reduce the risk of death from residential fires, but there are conflicting data regarding the impact of community-based smoke alarm installation programmes.

- There are no outcome studies of the efficacy of such programmes that used lithium-powered smoke alarms

- The duration of efficacy of community-based installation programmes is not known.

\section{What this study adds}

- This community-based smoke alarm installation programme was highly effective for residents of houses that received a smoke alarm, for the first 5-6 years after installation, but its efficacy declined substantially after that time.

- Most cases of house fire-related deaths and injuries in programme houses occurred in houses where the programme smoke alarm either did not work, or had been removed.

- Based on this data, smoke alarm installation programmes may not be able to plan on efficacy remaining high for the full 10 years that lithium powered alarms are advertised to work.
Acknowledgements We are indebted to the following people, without whose assistance Operation Installation and its evaluation could not have been done: Chief Joe Pierce, Captain Calvin Nichols, Captain Linda Henry, Chief Kevin Sipes, Sharon Smith (deceased), Delisa Seals and Celia Salazar of the Dallas Fire Rescue Department; Mary Brownlee of The Southwestern Institute of Forensic Sciences, Office of the Medical Examiner; Don Myatt and Vivian Zheng of the University of Texas Southwestern Medical Center, Department of Emergency Medicine Education; Cheryl Sutterfield-Jones of the Dallas Chapter of the American Red Cross; and Allen Bolton, former director of the IPC.

Contributors GRI, MAM, CR, SS-S, DKC, MS and RJA contributed to the concept and design of the project. MAM, CR and JJB contributed to the collection the data. GRI, MAM and BJM collaborated on the analyses, interpreting the results and writing the article. SS-S, DKC, MS and RJA provided administrative support for the project. GRI and MAM had access to all data and are responsible for the overall content. All authors reviewed and approved the final version.

Funding Funded in part from grant 1 H28 CE000840-01, National Center for Injury Prevention and Control, Centers for Disease Control, US Department of Health and Human Services, and from Subcontract \#727922 from The University of Washington, Seattle, Washington.

\section{Competing interests None.}

Ethics approval This study was deemed to have exempt status by the University of Texas Southwestern Medical Center Institutional Review Board.

Provenance and peer review Not commissioned; externally peer reviewed.

\section{REFERENCES}

1 Karter MJ. Fire loss in the United States during 2010. Quincy, MA: National Fire Protection Association, Fire Analysis and Research Division, 2011.

2 Sidman EA, Grossman DC, Mueller BA. Comprehensive smoke alarm coverage in lower economic status homes: alarm presence, functionality, and placement. J Community Health 2011;36:525-33.

3 Ahrens M. Smoke alarms in U.S. home fires. Fire analysis and research division. Quincy, MA: National Fire Protection Association,2011.

4 Liu Y, Holland AE, Mack K, et al. Disparities in the prevalence of smoke alarms in U.S. households: conclusions drawn from published case studies. I Safety Res 2011;42:409-13.

5 Harvey PA, Aitken M, Ryan GW, et al. Strategies to increase smoke alarm use in high-risk households. J Community Health 2004;29:375-85.

6 Ballesteros MF, Jackson ML, Martin MW. Working toward the elimination of residential fire deaths: the Centers for Disease Control and Prevention's Smoke Alarm Installation and Fire Safety Education (SAIFE) program. J Burn Care Rehabil 2005;26:434-9

7 Ta VM, Frattaroli S, Bergen G, et al. Evaluated community fire safety interventions in the United States: a review of current literature. J Community Health 2006;31:176-97.

8 Mallonee $S$, Istre GR, Rosenberg $M$, et al. Surveillance and prevention of residential fire-related injuries. N Engl J Med 1996;335:27-31.

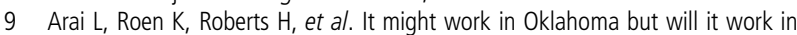
Oakhampton? Context and implementation in the effectiveness literature on domestic smoke detectors. Inj Prev 2005;11:148-51.

10 Warda L, Tenenbein M, Moffatt MEK. House fire injury prevention update. Part II. A review of the effectiveness of preventive interventions. Inj Prev 1999:5:217-25. 
11 DiGuiseppi C, Higgins JPT. Systemic review of controlled trials of interventions to promote smoke alarms. Arch Dis Child 2000;82:341-8.

12 Istre G, McCoy MA, Osborn L, et al. Deaths and injuries from house fires. N Engl J Med 2001;344:1911-16.

13 McCoy MA, Roper C, Campa E, et al. How long do smoke alarms function? A follow-up survey of a smoke alarm installation program. Inj Prev 2014;20:103-7.

14 Martin DO, Austin H Exact estimates for a rate ratio. Epidemiology 1996;7:29-33.

15 Conover WJ. Practical nonparametric statistics. 3rd edn. New York: Wiley, 1999.
16 DiGuiseppi C, Roberts I, Wade A, et al. Incidence of fires and related injuries after giving out free smoke alarms: cluster randomized controlled trial. BMJ 2002:325:995-9.

17 Jackson M, Wilson J, Akoto J, et al. Evaluation of fire-safety programs that use 10-year smoke alarms. J Community Health 2010;35:543-8.

18 Haddix AC, Mallonee S, Waxweiler R, et al. Cost effectiveness analysis of a smoke alarm giveaway program in Oklahoma City, Oklahoma. Inj Prev $2001 ; 7: 276-81$

\section{US children injured or killed by guns annually}

Yale University researchers, in a paper in Paediatrics, estimated that firearm injuries sent 7391 children to the emergency room in 2009 and $6 \%$ of them died. The damage caused by gun-related injuries rarely gets the same attention as fatalities, with the most common firearm injuries being open wounds, fractures and internal injuries of the thorax, abdomen or pelvis. (noted by IBP).

\section{Alberta researchers aim to reduce youth sports injuries by $20 \%$ in 5 years}

Top injury prevention researchers in Alberta, along with community partners (Hockey Canada and WinSport) aim to reduce youth sport injuries by $20 \%$ by 2020 . The initiative is led by Carolyn Emery and Brent Hagel and will focus on ice hockey, skiing and snowboarding, and junior high school phys-ed programmes. The initiative will build capacity by creating an interdisciplinary group of researchers including 20 international experts. What is perhaps most significant about this initiative is the inclusion of a fixed goal that may actually be achievable. (noted by IBP).

\section{Child car seats in the USA may be required for protection in side-impact crashes}

The National Highway Traffic Safety Administration seeks to improve child car seats by including a test that simulates a side crash. The agency estimates the new standards would prevent the deaths of about five children, and injuries to 64 others, every year. A safety advocate, applauding the proposal, called the estimate 'very, very conservative'. Safety advocates have long sought tougher side-impact standards for child car seats. (The Associated Press) (noted by IBP). 